\title{
Uso e abuso de drogas entre universitários e a sua interface com as políticas públicas*
}

\author{
Elisa Carneiro Pereira Camargo $0^{1,3}$ \\ (D) https://orcid.org/0000-0002-5890-1501 \\ Jamila Souza Gonçalves ${ }^{2,4}$ \\ (D) https://orcid.org/0000-0003-4565-8909 \\ Adriana Olimpia Barbosa Felipe e $^{3,4,5}$ \\ (D) https://orcid.org/0000-0002-4491-5750 \\ Silvana Maria Coelho Leite Fava ${ }^{4,5}$ \\ (D) https://orcid.org/0000-0003-3186-9596 \\ Márcia Maria Fontão Zago 6 \\ Di https://orcid.org/0000-0001-6539-2584 \\ Eliza Maria Rezende Dázio ${ }^{5}$ \\ (iD) https://orcid.org/0000-0001-9216-6283
}

\footnotetext{
Artigo extraído de dissertação de mestrado "Significado da droga entre universitários e a sua interface com as políticas públicas" apresentada à Universidade Federal de Alfenas, Escola de Enfermagem, Alfenas, MG, Brasil.

1 Prefeitura Municipal, Estratégia Saúde da Família, Monsenhor Paulo, MG, Brasil.

2 Instituto Federal de Educação Ciência e Tecnologia do Sul de Minas, Passos, MG, Brasil.

${ }^{3}$ Bolsista da Coordenação de Aperfeiçoamento de Pessoal de Nível Superior (CAPES), Brasil.

${ }^{4}$ Bolsista da Fundação de Amparo de Pesquisa de Minas Gerais (FAPEMIG), Brasil.

5 Universidade Federal de Alfenas, Alfenas, MG, Brasil.

${ }^{6}$ Universidade de São Paulo, Escola de Enfermagem de Ribeirão Preto, Centro Colaborador da OPAS/OMS para o Desenvolvimento da Pesquisa em Enfermagem, Ribeirão Preto, SP, Brasil.
}

Objetivo: analisar o significado do uso e do abuso de álcool e/ou de outras drogas entre os universitários em consonância com as políticas públicas brasileiras sobre drogas. Método: participaram 49 universitários de uma Instituição Pública de Ensino Superior da região Sudeste do Brasil. Resultados: pela Análise de Conteúdo de Bardin elaborou-se a categoria analítica: "Dissonância entre as políticas públicas e o significado do uso de drogas entre universitários". O uso e o abuso de drogas inicia-se na adolescência; estimulado pelos familiares e amigos, e remete à felicidade e à fuga dos problemas. Conclusão: é fundamental conhecer o significado do uso e do abuso de drogas, sob a ótica do universitário para a elaboração e a implementação de políticas públicas.

Descritores: Estudantes; Universidade; Abuso de Drogas; Políticas Públicas.

\section{Como citar este artigo}

Camargo ECP, Gonçalves JS, Felipe AOB, Fava SMCL, Zago MMF, Dázio EMR. Drug use and abuse among university students and interface with public policies. SMAD, Rev Eletrônica Saúde Mental Álcool Drog. 2019;15(4):1-9. doi: https://dx.doi.org/10.11606/issn.1806-6976.smad.2019.000364 


\title{
Drug use and abuse among university students and their interface with public policies
}

\begin{abstract}
Objective: to analyze the meaning of the use and abuse of alcohol and / or other drugs among university students in accordance with Brazilian public policies on drugs. Method: 49 university students from a Public Institution of Higher Education in the Southeast region of Brazil participated. Results: Bardin's Content Analysis elaborated the analytical category: "Dissonance between public policies and the meaning of drug use among university students". Drug use and abuse begin in adolescence; Stimulated by family and friends, and refers to the happiness and flight of problems. Conclusion: it is fundamental to know the meaning of drug use and abuse, from the perspective of the university for the elaboration and implementation of public policies.
\end{abstract}

Descriptors: Students; University; Drug Abuse; Public Policy.

\section{Uso y abuso de las drogas entre los universitarios y su interfaz con las políticas públicas}

Objetivo: analizar el significado del uso y abuso de alcohol y otras drogas entre los estudiantes Universidad en línea con Brasil las políticas públicas sobre drogas. Método: los participantes fueron 49 estudiantes de una institución pública de educación superior en la región sureste de Brasil. Resultados: el análisis de contenido de Bardin elaboraran categoría analítica era: "Disonancia entre política públicas y el significado del uso de drogas entre los estudiantes universitarios." El uso y abuso de drogas comienza en la adolescencia; alentado por familia y amigos, la felicidad y el escape de los problemas. Conclusión: es imprescindible conocer el significado del uso y abuso de drogas, desde la perspectiva de la Universidad para el desarrollo y la implementación de políticas públicas.

Descriptores: Estudiantes; Universidad; Abuso de Drogas; Políticas Públicas. 


\section{Introdução}

Na contemporaneidade o uso e o abuso de drogas entre jovens, especialmente, universitários constitui problema de saúde pública e exige do Estado, das universidades e de toda a sociedade ações para a prevenção e o controle desse fenômeno(1-2).

$O$ ingresso no ensino superior pode representar para a maioria dos acadêmicos a oportunidade de conquistar a formação profissional desejada. Permite aos jovens a mudança de ambiente social, familiar e escolar e, para muitos, representa o início da administração de suas vidas sozinhos(3). No entanto, esse ingresso pode constituir um momento de estresse e tornar alguns estudantes mais vulneráveis a comportamentos de risco, como o consumo de álcool e/ou de outras drogas, uma vez que eles se afastam do meio familiar e se associam aos pares, em decorrência da necessidade de fazer novas amizades, de adaptação em uma nova moradia, de gerenciar a liberdade estabelecida(2).

Despertou a nossa atenção o fato de que no cotidiano da vida universitária determinados estudantes apresentam mudanças de comportamento, se mostram tristes, deprimidos, revoltados, eufóricos ou até mesmo indiferentes, inclusive faltam às atividades propostas. A nosso ver, tais comportamentos impõem à universidade e aos docentes, atitudes, não de discriminação, mas sim de acolhimento, principalmente quando estiverem relacionados ao uso de substâncias psicoativas, pois não basta à educação superior primar pelo avanço do conhecimento científico e pela utilização das tecnologias de informação e comunicação para a formação do profissional culto, crítico, reflexivo, é premente a formação do cidadão e de valores para a vida ${ }^{(4)}$. Para tanto, é fundamental o estabelecimento de vínculo entre professor-aluno e que os educadores ofereçam alternativas que possibilitem aos jovens a capacidade de enfrentar os desafios impostos em suas vidas, nesta faixa etária, como a prevenção e a redução do consumo de drogas ${ }^{(4)}$.

Dada a magnitude do problema do uso e do abuso dessas substâncias entre os universitários, torna-se imprescindível conhecer a compreensão que o estudante universitário tem a respeito do uso e do abuso de álcool e /ou de outras drogas. Assim, sugiram as seguintes inquietações: $O$ que o universitário pensa sobre a droga? O que a droga oferece a ele? Qual o motivo de as políticas públicas não serem eficazes? O que poderia ser feito nas universidades para prevenir ou minimizar o consumo de droga entre os universitários?

Nesse contexto, este estudo tem como objetivo analisar o significado do uso e abuso de álcool e/ou de outras drogas entre os universitários, em consonância com as políticas públicas brasileiras sobre drogas.

Estudos ressaltam a necessidade de realizar pesquisas acerca do consumo de álcool e/ou de outras drogas entre os universitários, que contribuam para a percepção desse fenômeno, e ao mesmo tempo sirvam para detectar os recursos e vulnerabilidades desse grupo(1,4-5). Destaca-se ainda que é de suma importância o desenvolvimento de estudos dessa natureza, que ofereçam subsídios para programas de prevenção primária e secundária para essa população, uma vez que o papel da universidade é gerar mudança social(5).

\section{Método}

Trata-se de estudo de abordagem qualitativa, de caráter descritivo, fundamentado nas políticas públicas brasileiras sobre álcool e/ou outras drogas, no qual analisou-se os dados obtidos em dois estudos intitulados "Significado do uso de álcool e/ou drogas entre universitários" estudo 1 e "Significado do uso de álcool e/ou drogas entre universitárias" estudo 2, desenvolvidos anteriormente pelas pesquisadoras. Ambos os estudos foram desenvolvidos em uma universidade pública da região Sudeste do Brasil, que oferece cursos de graduação, na modalidade presencial e a distância e de pós-graduação lato e stricto sensu. A seleção dos participantes do estudo 1 foi realizada de acordo com os seguintes critérios de inclusão: universitários do sexo masculino, maiores de 18 anos, regularmente matriculados nos cursos de graduação presencial, que na época fizessem uso de álcool e/ ou de qualquer outra droga. Os critérios de seleção do estudo 2 foram os mesmos, porém com participantes do sexo feminino.

Para a realização dos dois estudos solicitou-se o consentimento da Pró-Reitora de Graduação da Universidade, busca pelos universitários em salas de aula, bem como esclarecimento quanto aos objetivos dos estudos. Os universitários que concordaram com participação, procuraram pelas pesquisadoras, foram esclarecidos novamente sobre os objetivos. A seguir, foi agendado um horário para entrevistas, na universidade ou nas residências.

A coleta de dados ocorreu no período de novembro de 2014 a julho 2015 por meio de um formulário para a coleta de dados referente aos aspectos socioeconômicos e das seguintes questões norteadoras para entrevista: "Fale como é para você ser universitário e fazer uso de bebida alcoólica e/ou de outras drogas" estudo 1 e "Fale como é para você ser universitária e fazer uso de bebida alcoólica e/ou de outras drogas" estudo 2. Utilizou-se das técnicas de entrevistas; observação participante e anotações em diário de campo. As entrevistas realizadas pelas autoras dos estudos 1 e 2, ocorreram em dia, horário e local de preferência dos participantes. Em média foram realizadas duas a três entrevistas por participante, com duração de 40 minutos, gravadas em MP4. 
Imediatamente após a realização, as entrevistas foram transcritas na íntegra pelas pesquisadoras, enumeradas em conformidade com a sequência em que foram realizadas, analisadas e arquivadas eletronicamente, utilizando-se o Programa Word. A observação participante e o diário de campo foram registrados em diversos momentos de encontros com os universitários em vários ambientes.

No presente estudo os depoimentos dos participantes foram avaliados mediante análise de conteúdo com a técnica de análise temática seguindo as fases de pré-análise, exploração do material e conversação dos resultados com a inferência e a interpretação(6).

Destaca-se que o estudo foi aprovado pelo Comitê de Ética e Pesquisa em Seres Humanos da Universidade Federal de Alfenas, sob o parecer no 822.626. Assim, todos os preceitos éticos e legais que envolvem a pesquisa em seres humanos regulamentados pela Resolução n0466/12, do Conselho Nacional de Saúde foram observados e respeitados. Os participantes assinaram do Termo de Consentimento Livre e Esclarecido - TCLE e receberam nomes fictícios, à escolha das pesquisadoras.

\section{Resultados e Discussão}

Participaram da investigação 49 universitários matriculados regularmente nos cursos de graduação de uma universidade pública da região sudeste do Brasil. Destes, 20 do sexo masculino e 19, do feminino, na faixa etária compreendida entre 20 e 32 anos, a maioria solteira, branca e católica. Houve o predomínio de renda familiar de quatro salários mínimos e 29 declararam morar em repúblicas. Quanto à renda pessoal, um participante mencionava exercer atividade laboral; 37 eram dependentes dos pais, 14 eram bolsistas, destes, nove eram de iniciação científica e um do Programa de Educação Tutorial - PET. Dois participantes informaram ter uma bolsa no valor de $\mathrm{R} \$ 400,00$ como única renda, uma vez que não recebem mais nenhum recurso financeiro para se manterem na universidade. Todos os participantes encontravam-se matriculados regularmente entre o $2^{\circ}$ e $010^{\circ}$ período dos cursos; 21 informaram apresentar ao menos uma dependência em disciplina; 21 eram da área de Ciências da Saúde, sendo que do total de participantes 12 já frequentaram outro curso. Com o intuito de responder aos nossos questionamentos encontrou-se a seguinte categoria analítica: Dissonância entre as políticas públicas e o significado da droga para os universitários.

O álcool por ser considerado uma substância lícita, é legalmente aceito e tolerado, isso contribui para que os jovens tenham a concepção de que ela não causa problemas. Há que se considerar que a fácil obtenção e disseminação dessa substância colaboram para o uso e o abuso(7). Os depoimentos a seguir ilustram a realidade do consumo de álcool e/ou de outras drogas entre os universitários:

[...] Faço consumo de álcool e cigarro... agora o álcool foi antes da faculdade, em casa a gente bebe vinho, mas cerveja não se bebe em casa. Ai experimentei com meus tios sabe...depois com meus amigos na rua, barzinho e depois na faculdade (E1 Augusto); [...] Bebo doses não muito, tipo eu bebo pinga porque meu avô bebia pinga na hora do almoço e deixava o restinho e empurrava pra mim para eu beber, e eu gosto, me traz uma memória boa. Uma recordação boa (E1 Jeane).

Os depoimentos dos universitários revelaram que, muitas vezes, o álcool é inserido na vida dos jovens em idade precoce através da família e dos amigos. Estudos verificaram que o uso e o abuso de álcool e/ou de outras drogas está associado ao exemplo vivenciados na família e com os pares ${ }^{(8-9)}$. Cabe ressaltar que os exemplos são os maiores reforços para o aprendizado entre os jovens $^{(8)}$. Estes dados apontam um caminho perigoso em que estes podem vir a trilhar, uma vez que o consumo da droga estimulado pelos familiares e amigos faz com que esse processo seja algo natural, sem consequências para a sua vida(10).

O Ministério da Saúde compartilha a ideia de que o consumo de álcool e/ou de outras drogas entre os membros da família e dos grupos de pares constitui fator de risco e retrata a necessidade de assistência aos familiares de dependentes ${ }^{(11)}$. Inclusive, o Plano Emergencial de Ampliação do Acesso ao Tratamento e à Prevenção em Álcool e outras Drogas (PEAD), separa o álcool de outras drogas e parece revelar que o álcool não é droga. Por outro lado, apreende-se que, para evitar maiores transtornos e discriminação em relação ao tratamento das pessoas que usam e abusam bebidas alcoólicas, foi realizada a separação(12).

Acrescenta-se que o consumo de bebida alcoólica é naturalizado e valorizado socialmente, e está associado as festividades, ao lazer, ao relaxamento, à diversão, ao fortalecimento de vínculo com os pares, ao esquecimento dos problemas vivenciados, a liberdade e o $\operatorname{prazer}^{(9,13)}$, como constatado nos seguintes depoimentos:

[...] então eu tenho o álcool na minha vida como um certo tipo de lazer quando eu estou com os meus amigos, quando eu vou na festa, saio à noite, quando estou com minha namorada... não tem um motivo muito certo, mas eu gosto, eu acho cerveja gostosa [...] se eu for pra sentar em um lugar e beber duas cervejas para conversar eu faço isso, acho que é agradável e um costume que a gente vai criando assim às vezes. E ah a gente fica mais bêbado assim, mas solto não porque eu já sou assim..rs (E1 Marcelo); [...] Nossa não sei, o álcool eu sempre 
lembro estar com os amigos, comemorar, conversar. Como eu não exagero é felicidade (E1 Carla).

Pode-se inferir que, para a obtenção do prazer e da felicidade, os jovens universitários, elegem o álcool como droga de escolha para minimizar a pressão do dia a dia. Nesta modalidade de pensamento consumir bebida alcoólica faz parte da rotina desses jovens, o que se torna preocupante, uma vez que, esse consumo estabelece uma linha tênue entre o consumo recreativo e a dependência(13).

Torna-se relevante considerar que o uso e o abuso de álcool pelos universitários tem a finalidade de minimizar a timidez e assim, agregar relações sociais com os pares. Isso foi ressaltado nos depoimentos abaixo:

[...] Pra mim o que leva o universitário a usar além das sensações é o ambiente, usa também para ficar mais desinibido. E conforme bebe tudo fica mais gostoso (E1 Paulo); [...] Eu acho que o álcool querendo ou não, ele aproxima as pessoas, te deixa mais solto para conversar, deixa mais desinibido para algumas coisas, eu acho que aproxima, tanto falando desta faixa etária que a gente tá, deixa mais desinibido para chegar e conversar coisas ...que às vezes estivesse sem bebida ou por uma personalidade mais tímida não faria (E1 Marcelo).

Os universitários descrevem que a euforia e a desinibição são efeitos do álcool(14). Os depoimentos evidenciam que o uso e o abuso de álcool e/ou de outras drogas é também referenciado pelos jovens como uma forma de amenizar os problemas vivenciados:

[...] eu tomo álcool mesmo para extravasar, ou tomo uma porque estou com muita coisa na cabeça, você toma um pouco e esquece né (E1 Julio); [...] Acho que (a droga) é uma coisa que você usa para melhorar o momento (E1 Flávia).

Os dados encontrados são coerentes com a literatura, ao enfatizar que esse consumo é uma das maneiras de minimizar a dor, o sofrimento, as frustrações e as perdas que ocorrem no cotidiano. Os jovens utilizam essas substâncias na tentativa de aliviar a angústia desencadeada pela fragilidade dos vínculos familiares, contudo o uso e o abuso destas provocam mais conflitos no ambiente familiar ${ }^{(15)}$. A Política Nacional do Ministério da Saúde para Atenção Integral aos usuários de álcool e outras drogas ressaltam a importância da entidade familiar estar preservada e da otimização do contato entre esses membros como forma de proteção ao uso e ao abuso dessas substâncias ${ }^{(11)}$.

Mediante tal constatação, é fundamental que as instituições de ensino realizem investigações sobre o bem-estar e a saúde mental dos estudantes e planejem ações efetivas nesse processo, minimizando os efeitos dessas alterações e do uso e do abuso de álcool e/ou de outras drogas como tentativa de restaurar o bem estar. O Plano Nacional de Assistência Estudantil já determina que uma das áreas prioritárias na assistência aos jovens universitários é assistência psicopedagógica e à dependência química(16). Deste modo, é relevante mencionar a necessidade de programas educativos na conscientização dos universitários e a inserção da Politica Nacional do Álcool e outras drogas, assim como as leis vigentes no país para compreensão desse fenômeno(1,9). Recomenda-se que todo esse processo tenha o envolvimento da família e da rede de apoio com o objetivo de dialogar entre os diversos atores sociais(4). Ressalta-se que o comércio de bebidas alcoólicas é legal para maiores de 18 anos(11), porém essa maioridade de consumo não é cumprida(17). O que é reiterado no seguinte depoimento: [...] Questão de bebida por exemplo, com 15 anos eu comecei a beber em casa e sair com amigos, mas o meu pai falava você pode experimentar sem abusar (E1 Paulo).

Parece haver um abismo entre o cumprimento dessa lei e o uso e o abuso de álcool, uma vez que, os jovens menores de 18 anos o consomem por meio do compartilhamento entre os amigos e os familiares ${ }^{(9)}$.

Destaca-se que a Política Nacional do Ministério da Saúde para Atenção Integral aos usuários de álcool e outras drogas de 2004 e o decreto No 6.117, de 22 de maio de 2007, o qual visa regulamentar, controlar, fiscalizar e restringir as propagandas referentes ao uso de bebida alcoólica(11,18). Contudo nem sempre essas legislações são reconhecidas, uma vez que as publicidades raramente passam por fiscalizações. Um fato ressaltado entre os participantes: [...] a gente sabe (das festas com bebida na faixa) por propagandas (E1 Marcelo).

A literatura vem associando o comportamento dos jovens em relação ao uso e ao abuso de bebidas alcoólicas com as mensagens transmitidas pelas mídias. Assim, possivelmente a limitação da veiculação dessas propagandas pode ser um dos caminhos para a prevenção e a redução do uso e do abuso do álcool(19).

Salienta-se que dada a permissividade do uso e do abuso de álcool e/ou de outras drogas entre os universitários, uma parcela da população também coaduna com essa premissa e até aproveita para que isso seja revertido em lucro, com a organização de festas.

[...] Nesta cidade não tem como, né! Aqui é outra realidade! Pelo menos na minha cidade, eu não tinha contato com esse meio universitário. Olha que na minha cidade tem faculdade, tem (nome da universidade) e tal, mas é outra realidade. Nesta cidade tem muita festa! Muita festa! (E1 Alexandre); [...] A maioria das festas aqui é open bar, as festas aqui são voltadas a open bar, ao consumo de álcool. O consumo de open bar é muito grande, bebo mais quando vou nessas festas mas não bebo excessivamente (E1 Pedro). 
A participação dos universitários em festas é um hábito corriqueiro e o uso, bem como abuso de álcool e ou/ de outras substâncias ${ }^{(1)}$. Ainda, com relação ao ambiente, as festas, os shows, os bares são os locais preferidos para o uso e para o abuso de álcool e/ou de outras drogas entre universitários. Estudo ressalta a necessidade de controlar as festas com bebidas liberadas, como também a disponibilidade do álcool com preço reduzido em eventos estudantis e bares próximos à universidade ${ }^{(9)}$.

O ingresso na universidade é permeado por inúmeras mudanças, pelas oportunidades e pelo estabelecimento de novos vínculos sociais que influenciam o comportamento desses acadêmicos como referenciado a seguir:

\section{[...] Então quando eu não estava na faculdade eu experimentava,} mas não fazia o uso assim. Agora depois que entra na faculdade você começa a beber mais socialmente, e festa com amigos, reunião; ai a gente toma um pouco mais, antigamente não (E1 Ricardo); [...] A maconha também é uma certa forma de socialização e o pessoal consome bastante por aqui (E1 Josiel).

Parece possível supor que na história dos universitários o uso e o abuso de álcool e/ou de outras drogas é uma realidade do dia a dia. Contudo, esse uso não tem origem na universidade, visto que, a maioria dos estudantes já experimentaram antes do seu ingresso no ensino superior ${ }^{(14,20)}$. Mas é neste ambiente que o uso e o abuso dessas substâncias ficam mais acentuados e arriscados, manifestando problemas relacionados a esse padrão de consumo(21), conforme descrito a seguir:

[...] Então quando eu não estava na faculdade eu experimentava, mas não fazia o uso assim. Agora depois que entra na faculdade você começa a beber mais socialmente, e festa com amigos, reunião; aí a gente toma um pouco mais antigamente não (E1 Ricardo).

É importante considerar que a adolescência é um momento de busca de novas experiências, de individualização, de amadurecimento e que o uso e o abuso de álcool e/ou de outras drogas podem estar presentes.

O fato de os universitários afirmarem ter autocontrole em relação ao uso e ao abuso de álcool e/ ou de outras drogas constitui-se um fator preocupante, tendo em vista o risco de dependência dessas substâncias:

[...] a maconha pode atrapalhar um pouco se você não souber a hora do lazer e a de você estudar (E1 Pedro); [...] é que eu sou acostumada a beber, eu sou forte pra beber. Aí como eu sou forte a turma já lascou umas três em mim, pra mim beber e eu estava firme e forte (E1 Larissa)
Os depoimentos revelaram que os universitários referem estratégias de autocontrole para o uso de substâncias psicoativas. Entretanto, acredita-se que nem sempre eles fazem uso dessas estratégias, pois investigações conduzidas com essa população verificaram uma taxa representativa em consumo problemático de álcool e /ou de outras drogas ${ }^{(5,22)}$.

Percebeu-se que os universitários apresentam conhecimento quanto aos malefícios do uso e do abuso de álcool e/ou de outras drogas, apenas em circunstâncias abusivas.

[...] a gente vê falar que o álcool não é bom, claro que não é bom, na minha área mesmo o álcool junto com o cigarro ele potencializa o câncer de boca, isso é uma coisa que é muito prejudicial. Mas creio eu que bebendo conscientemente ele não trará tanto prejuízo, quanto um consumo excessivo (E1 Marcelo).

Apesar de os jovens ressaltarem os malefícios deste consumo, eles se deparam com a curiosidade em vivenciar o novo, não se lembrando da possibilidade da adição desde o contato inicial com a droga ${ }^{(15)}$. Contudo, a literatura vem reportando que a população jovem percebe o uso e o abuso de drogas lícitas e ilícitas como inofensivas à sua saúde(20).

Embora os cursos de graduação abordem a temática referente aos riscos do uso e do abuso de álcool, essa abordagem parece não ter impacto positivo em relação a este consumo entre os universitários ${ }^{(9)}$. Mediante tal situação, o uso e o abuso de álcool e/ou de outras drogas deve ser prioridade nas instituições de ensino, incluindo além de disciplina obrigatória, apoio psicopedagógico e atividades extensionistas com programas de orientação e de prevenção(22). A abordagem dessa temática deva ser transversal em todos os conteúdos(14). É importante considerar que essa estratégia deve estar em consonância com as políticas públicas sobre álcool e drogas vigentes no país.

O uso e o abuso de álcool e/ou de outras drogas pode causar diferentes danos ao usuário e à sociedade. No entanto, os participantes fizeram os seguintes depoimentos:

[...] agora maconha pode atrapalhar como você pode levar a sua rotina de estudo (E1 Pedro); [...] Já dirigi, mas muito alcoolizado e muito transtornado não...sabe eu tenho níveis eu me conheço (E1 Alexandre).

Verifica-se que os universitários podem desenvolver comportamentos de risco associados ao uso e ao abuso de álcool e/ou de outras drogas, entre eles, a direção de veículos sob o efeito de bebidas alcoólicas ${ }^{(9)}$, apesar da existência da Lei "Lei Seca", que fixa penalidades mais rígidas para o motorista que transitar sob a interferência de álcool ou outra substância psicoativa que determine dependência(23). Deduz-se que somente a legislação 
não é suficiente para inibir tais comportamentos, pois culturalmente existe um "jeitinho brasileiro" para burlar a legislação. Fica evidente a necessidade de se trabalhar com os jovens universitários a conscientização, sem repressões, para a formação do cidadão.

Com relação ao desempenho acadêmico, a bibliografia reporta que os universitários têm a ciência que o uso e o abuso de álcool e/ou de outras drogas causam prejuízos( ${ }^{(2)}$. No entanto, mesmo tendo consciência, muitos fazem uso de drogas.

Outra questão preocupante refere ao uso indiscriminado de medicamentos psicotrópicos entre os universitários:

[...] A ritalina comecei a tomar, porque eu vi que meu rendimento na faculdade não estava bom, era diferente dos meus colegas, eu tinha dificuldades para me concentrar... essa eu pretendo parar de usar assim que eu terminar a faculdade e não precisar mais tanto dela (E1 Igor).

Há evidências na literatura de um alto índice de universitários utilizando essa substância descrita nesse depoimento, com o objetivo de aumentar a concentração e o rendimento nas atividades acadêmicas(24). Não habituados com as adversidades, os jovens utilizam esses medicamentos para melhor enfrentamento do sofrimento, da dor e da perda do autocontrole(15). A nosso ver torna-se imprescindível uma revisão de todo o processo de educação em nosso país e o Estado e os docentes coadunam com essa questão. Para tanto, é premente que o educador e o educando sejam sujeitos ativos da prática educativa para a construção de saberes permeada por relações democráticas, com vistas à autonomia do educando e formação do cidadão(25).

Apreende-se pela análise dos depoimentos em confronto com as políticas públicas brasileiras sobre o uso de álcool e de outras drogas, inclusive medicamentos usados indiscriminadamente por eles, que existe um grande desafio a ser enfrentado pelo Estado, pelas universidades, pelos docentes, pelos universitários, pelos familiares e pela sociedade em geral.

\section{Conclusão}

Este estudo revelou que o uso e o abuso de álcool e/ou de outras drogas entre universitários remete ao prazer, à felicidade, à facilitação das interações sociais e à fuga dos problemas. Reitera-se que o uso e o abuso de drogas constitui um problema de saúde pública no Brasil e no mundo, principalmente entre os universitários.

Dada a magnitude da temática, o Estado vem investindo na elaboração e na implementação de políticas públicas com vistas à prevenção e à redução do consumo de drogas, especialmente entre jovens universitários, pelo fato de consumirem mais substâncias psicoativas que a população em geral, na mesma faixa etária.

Nesse contexto, para minimizar a dissonância, sugere-se que as políticas públicas sejam elaboradas e implementadas de forma a ir "ao encontro" e não "de encontro" com as concepções dos estudantes. Buscar por ações que permitam ao acadêmico ser ouvido em sua dimensão existencial e ao mesmo tempo prezar pela sua autonomia.

Somente a educação emancipadora, comprometida com a formação do sujeito crítico e reflexivo resultará na capacidade de escolhas, na incorporação de novos significados ao seu processo de existir e, por conseguinte, a prevenção. Para tanto, é necessário promover a capacitação dos servidores para lidar com a situação, uma vez que, cada um de nós deve estar despido de preconceitos e de juízo de valores e ao mesmo tempo pensar que para eles a droga remete à felicidade e faz parte da passagem deles pela universidade.

Finalizamos reiterando que o uso e o abuso de drogas motivam a desagregação social, a violência e os crimes, mas é premente repensar e implementar políticas públicas comprometidas com a justiça social e com a extirpação da iniquidade.

Este estudo tem como limitações ter sido realizado em sua maioria, com universitários dos últimos períodos da graduação, sugere-se então, o desenvolvimento de estudos com universitários de períodos iniciais.

Recomenda-se também que as investigações sobre o uso e o abuso de álcool e/ou de outras drogas e a saúde mental dos estudantes sejam realizadas em outras universidades com o objetivo de avaliar a realidade de cada cenário e assim propor estratégias interventivas. Cabe destacar que o enfermeiro é um dos profissionais que pode auxiliar no diagnóstico da situação e na implementação dessas estratégias, corroborando para a qualidade de vida dessas pessoas.

\section{Referências}

1. Zeferino MT, Hamilton $H$, Brands B, Wright MGM, Cumsille F, Khenti, A. Consumo de drogas entre estudantes universitários: família, espiritualidade e entretenimento moderando a influência dos pares. Texto Contexto Enferm. [Internet] 2015 [Acesso 6 jul 2016];24(n. esp):125-35. Disponível em: http:// www.scielo.br/pdf/tce/v24nspe/0104-0707-tce-24spe-00125.pdf

2. Antoniassi G Júnior, Meneses-Gaya C. Implicações do uso de álcool, tabaco e outras drogas na vida do universitário. Rev Bras Promoção Saúde. 2015;28(1): 67-74.

3. Ramos SIV, Carvalho AJR. Nível de estresse e estratégias de coping dos estudantes do $1^{\circ}$ ano 
do ensino universitário de Coimbra. Rev Psicol. [Internet]. 2008 [Acesso15 abril 2014]:1-10. Disponível em: http://www.psicologia.pt/artigos/ textos/A0368.pdf

4. Moreira A, Vóvio CL, De Micheli D. Prevenção ao consumo abusivo de drogas na escola: desafios e possibilidades para a atuação do educador. Educ Pesqui, 2015;41(1):119-35.

5. Medeiros SB, Rediess SV, Hauck Filho N, Martins MIM, Mazoni CG. Prevalência do uso de drogas entre acadêmicos de uma universidade particular do sul do Brasil. Aletheia. 2012 [Acesso 8 jul 2016];38(39):81-93. Disponível em: http://pepsic.bvsalud.org/pdf/aletheia/ n38-39/n38-39a07.pdf

6. Bardin L. Análise de Conteúdo. Lisboa, Portugal; Edições 70; 2011.

7. Zeitoune RCG, Ferreira VS, Silveira HS, Domingos AM, Maia AC. O conhecimento de adolescentes sobre drogas lícitas e ilícitas: uma contribuição para a enfermagem comunitária. Esc Anna Nery. 2012;16(1):57- 63 .

8. Pereira MO, Silva SS, Oliveira MAF, Vargas D, Colvero LA, Leal BMML. A percepção dos adolescentes acerca do álcool e outras drogas no contexto familiar. SMAD, Rev. Eletrônica Saúde Mental Álcool Drog. [Internet]. set.-dez. 2011;7(3):148-54. [Acesso 12 dez 2016]: Disponível em: http://www.revistas.usp.br/smad/ article/view/49588/53706 doi:http://dx.doi.org/ 10.11606/issn.1806-6976.v7i3p148-154

9. Baungarten LZ, Gomes VLO, Fonseca AD. Consumo alcoólico entre universitários(as) da área da saúde da Universidade Federal do Rio Grande/RS: subsídios para enfermagem. Esc Anna Nery. 2012;16(3):530-5.

10. Alavarse GMA, Carvalho MDB. Álcool e adolescência: o perfil de consumidores de um município do norte do Paraná. Esc Anna Nery. 2006;10(3):408-16.

11. Ministério da Saúde (BR). Secretaria de Atenção à Saúde. SVS/CN-DST/AIDS. A Política do Ministério da Saúde para Atenção Integral a Usuários de Álcool e outras Drogas/Ministério da Saúde. 2.ed. Brasília: Ministério da Saúde; 2004.

12. Ministério da Saúde (BR). Portaria n01.190, de 4 de junho de 2009. Institui o Plano Emergencial de Ampliação do Acesso ao Tratamento e Prevenção em Álcool e outras Drogas no Sistema Único de Saúde SUS (Pead 2009-2010) e define suas diretrizes gerais, ações e metas. Diário Oficial da União. Brasília; 2009. 13. Santos ECV, Martin D. Cuidadoras de pacientes alcoolistas no município de Santos, SP, Brasil. Rev Bras Enferm. 2009;62(2):194-9.

14. Felipe ICV, Gomes AMT. Consumo de álcool entre acadêmicos da área da saúde: implicações para a prática profissional. Rev Enferm UERJ. 2014; 22(1):35-41.

15. Cardoso MP, Agnol RD, Taccolini C, Tansini K, Vieira $V$, Hirdesl A. A percepção dos usuários sobre a abordagem de álcool e outras drogas na atenção primária à saúde. Aletheia. [Internet]. 2014 [Acesso 26 dez 2016];(45):72-86. Disponível em: http:// pepsic.bvsalud.org/scielo.php?script $=$ sci_arttext \&pid $=S 1413-03942014000200006 \&$ Ing $=p t \& n r m=i s o$. 16. Fonaprace/Andifes. Revista 25 Anos do Fonaprace. Revista Comemorativa 25 anos: histórias, memórias e múltiplos olhares. Fonaprace (org.). Ufu, Proex, 2012. 17. Rocha FIF, Cardoso FC. O consumo de álcool entre os adolescentes na cidade de Araxá-MG: uma abordagem sociológica e jurídica. Rev Jurídica Uniaraxá. 2012;16(15):140-62.

18. Decreto n० 6.117, de 22 de maio de 2007 (BR). Aprova a Política Nacional sobre o Álcool, dispõe sobre as medidas para redução do uso indevido de álcool e sua associação com a violência e criminalidade, e dá outras providências [Internet]. Brasília, 22 de maio de 2007. [Acesso 5 jul 2016]: Disponível em: www.planalto.gov.br/ccivil_03/_ato2007-2010/2007/ decreto/d6117.htm

19. Faria R, Vendrame A, Silva R, Pinsky I. Propaganda de álcool e associação ao consumo de cerveja por adolescentes. Rev Saúde Pública. 2011;45(3):441-7. 20. Seguel PF, Santander MG, Ramos SML. Drug use and associated demographic factors of freshman students in a Chilean University. Acta Paul Enferm. 2012;25(n. esp):33-9. [Acesso em 2016 Jul 10]: Disponível em: <http://www.scielo.br/pdf/ape/ v25nspe2/06.pdf>.

21. Fachini A. Aspectos da vida acadêmica associados ao uso do álcool e outras drogas. Ribeirão Preto/USP, 2013. 143f. Tese (Doutorado em Medicina) - Faculdade de Medicina de Ribeirão Preto, Ribeirão Preto, 2013. Disponível em: <http://www.teses.usp.br/teses/ disponiveis/17/17148/tde-22102013-141513/pt-br.php>. Acesso em: 06 jul. 2016.

22. Moraes DPA, Medeiros GMR, Caldas AXB, Oliveira LA, Baldaça L. Prevalência do uso de drogas psicitrópicas por estudantes de medicina da Universidade Federal do Tocantins. Arq Med Hosp Fac Cienc Med Santa Casa São Paulo 2013;58(3):127-33.

23. Lei no 11.705/2008, de 19 de junho de 2008 (BR). Altera a Lei $n^{\circ}$ 9.503, de 23 de setembro de 1997, que institui o Código de Trânsito Brasileiro', e a Lei n 9.294, de 15 de julho de 1996, que dispõe sobre as restrições ao uso e à propaganda de produtos fumígeros, bebidas alcoólicas, medicamentos, terapias e defensivos agrícolas, e dá outras providências. Brasília, 19 de junho de 2008. Disponível em www. 
planalto.gov.br/ccivil_03/_ato2007-2010/2008/lei/

111705.htm Acesso em: 05 de jul. de 2016.

24. Coli ACM, Silva MPS, Nakasu MVP. Uso não Prescrito de Metilfenidato entre Estudantes de uma Faculdade de Medicina do Sul de Minas Gerais. Rev Ciênc Saúde. [Internet]. 2016 [Acesso 16 ago 2018]; 6(3). Disponível em: http://200.216.240.50:8484/ rcsfmit/ojs-2.3.3-3/index.php/rcsfmit_zero/article/ viewFile/582/377

25. Freire P. Pedagogia do oprimido. 43. ed. São Paulo: Paz e Terra; 2005. 